\title{
Retraction Note to: Effect of miR-451 on the Biological Behavior of the Esophageal Carcinoma Cell Line EC9706
}

\author{
Tao Wang ${ }^{1,2} \cdot$ Wen-qiao Zang ${ }^{3} \cdot{\mathrm{Min} \mathrm{Li}^{3} \cdot \mathrm{Na} \mathrm{Wang}^{3} \cdot \text { Yu-ling Zheng }}{ }^{1}$ Guo-qiang Zhao ${ }^{3}$
}

Published online: 19 October 2019

(c) Springer Science+Business Media, LLC, part of Springer Nature 2019

\section{Retraction Note to: \\ Dig Dis Sci (2013) 58:706-714 \\ https://dx.doi.org/10.1007/s10620-012-2395-x}

The Editor-in-Chief has retracted this article [1] because Figure 8 overlaps with Figure $6 \mathrm{~b}$ of [2] and Figure 6 overlaps with Figure 3 of [3] and Figure 3 of [4]. An investigation by Zhengzhou University has confirmed that these figures overlap. The data reported in this article are therefore unreliable. Guo-qiang Zhao does not agree with this retraction. The other authors have not responded to any correspondence about this retraction.

\section{References}

1. Wang T, Zang W, Li M, et al. Dig Dis Sci. 2013;58:706. https:// doi.org/10.1007/s10620-012-2395-x.

2. Zang W, Wang Y, Wang T, et al. Mol Cancer. 2015;14:37. https ://doi.org/10.1186/s12943-015-0315-3.

3. Yang Q, Li M, Wang T, et al. Diagn Pathol. 2013;8:132. https:// doi.org/10.1186/1746-1596-8-132.

4. Wang M, Wang Y, Zang W, et al. Tumor Biol. 2014;35:39. https ://doi.org/10.1007/s13277-013-1004-8.

Publisher's Note Springer Nature remains neutral with regard to jurisdictional claims in published maps and institutional affiliations.
The original article can be found online at https://doi.org/10.1007/ s10620-012-2395-x.

Yu-ling Zheng

zhengyuling1@sina.com

$\triangle$ Guo-qiang Zhao

zhaogq@zzu.edu.cn

Tao Wang

wang37127070@tom.com

Wen-qiao Zang

zangwenqiao@sina.com

Min Li

limin75@163.com

Na Wang

2012wangna@sina.com

1 Department of Tumor, The First Affiliated Hospital of Zhengzhou University, Zhengzhou 450052,

People's Republic of China

2 Department of Hemato-Tumor, The First Affiliated Hospital of Henan University of TCM, Zhengzhou 450000, People's Republic of China

3 Department of Microbiology and Immunology, College of Basic Medical Sciences, Zhengzhou University, Zhengzhou 450001, People's Republic of China 